\title{
THE CLINICAL SIGNIFICANCE OF GALLOP RHYTHM IN HYPERTENSION
}

\author{
BY \\ B. E. MILES \\ From the Department of Medicine, St. Thomas's Hospital \\ Received June 15, 1950
}

Gallop rhythm is widely held to be a sign of prognostic value, and this opinion has been supported by follow-up studies of patients with gallop rhythm in groups of mixed ætiology. This method of assessment is, however, open to criticism; first, because it is so dependent upon the way in which the patients are selected, and secondly, because the prognostic significance of gallop rhythm is clearly not the same in different diseases. This paper reports a clinical and phonocardiographic study of 100 hypertensive subjects, 37 of whom had gallop rhythm. The presence or absence of the various types of gallop has been correlated with the blood pressure, heart size, degree of cardiac failure, and electrocardiogram.

\section{DEFINITION AND NOMENClatURE}

Gallop rhythm is here defined as the presence, in a patient with heart disease, of audible vibrations in diastole, homologous either with the physiological third or auricular sounds. A phonocardiographic classification is used. The gallop sound coincident with the third sound which occurs during rapid ventricular filling, is called " rapid filling" gallop. That corresponding with the auricular sound and dependent upon auricular systole is called "auricular" gallop. A gallop occurring when diastole is so shortened by tachycardia that the rapid ventricular filling phase merges with auricular systole is called " indeterminate " gallop.

The use of the terms " rapid filling" and "auricular" gallop follows the classification used by Lian, Minot, and Welti (1941) and Frost (1949). They seem preferable to " protodiastolic" and "presystolic" gallop, since the former never occurs in protodiastole, and may even occur in the second half of diastole, whereas the latter is at times mid-diastolic. A second alternative, namely, subdivisions of the third sound and fourth sound (Evans, 1943), has the disadvantage that these may be confused with their physiological counterparts; it is also perplexing to call the earliest sound in the cardiac cycle the fourth. At all events, each of these three classifications should be confined to phonocardiographic diagnosis. Clinically, it is best to describe early, mid-, and late diastolic gallops. The term indeterminate gallop has been coined as no other suitable name exists. The summation gallop of Wolferth and Margolies (1931) originally referred to the gallop that may arise when subaudible protodiastolic and presystolic vibrations merge during tachycardia, and by summation become audible. It remains a valuable term when restricted to this connotation. The epithet " gallop" has been retained; it has survived its centenary.

\section{Clinical Material}

One hundred patients with hypertension were studied: 62 women and 38 men. All had average "casual " diastolic pressures above 95. Their average age was 57 years (range 18-80). The ætiological groups were as follows: essential hypertension 91 , chronic nephritis 3 , chronic pyelonephritis 2 , toxæmia of pregnancy 3 , and coarctation of the aorta 1 . 
Thirteen had angina pectoris and 35 were considered obese. Cases with valvular disease,. anæmia, thyrotoxicosis, substantial lung disease, or recent myocardial infarction were excluded. The patients derived from two sources; the cardiovascular clinic (47), and the medical wards (53) of the Dunedin Public Hospital, New Zealand. All available cases from the cardiovascular clinic were studied, and most of the cases from the wards. Patients with marked dyspnca at rest were usually excluded for technical reasons. Otherwise they were unselected. The majority were moderately severe or severe cases.

\section{METHODS}

Clinical interpretation of heart sounds. The patients, unless orthopnœic, lay supine on a couch. The heart was examined with a stethoscope at the apex and near the xiphisternum. A clinical diagnosis of any abnormal sound was recorded with the qualifications definite, probable, or possible, and the loudness and site of maximum audibility were noted. No special manœuvres were employed to try to bring out a gallop sound. The results of previous auscultation were ignored.

Apparatus and recording procedure. The apparatus used was a six-channel oscilloscope designed and constructed in the Department of Medicine of Otago University. The input was derived from a Maico Stethetron pick-up head and tracings were recorded on 35-mm. film. The frequency response curves corresponded closely with the linear, stethoscopic, and logarithmic curves recommended by Rappaport and Sprague (1942). Additional information about the instrument and its acoustic properties have been published elsewhere (Miles, 1950).

As a reference trace for timing phonocardiographic events, a standard lead II electrocardiogram was used: this was considered adequate in the present group of patients where the main difficulty was in distinguishing auricular gallops from split first sounds. Whilst recording the tracings, first at the apex and then in the xiphisternal region, the various channels were checked visually on the monitor oscilloscope, and at the same time the heart sounds were heard with the monitor stethoscope fed from the same pick-up head. About 18 inches of film were used for each patient.

Phonocardiographic interpretation of heart sounds. Audible vibrations beginning between $0 \cdot 11$ and $0.20 \mathrm{sec}$. after the onset of the second sound were considered to be rapid filling gallops. Those occurring between the apex of the $P$ wave and the apex of the $R$ wave in the reference electrocardiogram were considered to be auricular gallops. It is realized that these standards are arbitrary, and that some of the indeterminate gallops would have been classified as auricular gallops by other authors (Orías and Braun-Menéndez, 1939; Lian et al., 1941). These diagnoses were made from the logarithmic traces except in the few cases in which the logarithmic channel was not recording properly. Even so, it was not always possible to be certain what had actually been heard. A phonocardiograph can at best only show what is potentially audible. This difficulty sometimes arose when a small auricular vibration and also a split first sound were recorded in the same patient. Three specimen phonocardiograms are shown in Fig. 1.

Final diagnosis of heart sounds. Before gallop rhythm was finally accepted, it had to be both heard and recorded. The few heard but not recorded and vice versa were excluded.

\section{Grading OF Associated Findings}

Blood pressure. It was decided to use the more significant diastolic pressure rather than the more easily determined systolic. The average of several "casual" diastolic pressures was taken, the casual pressure being the lowest recorded after about five minutes with the patient at rest in the outpatient department or ward. In 64 patients a basal blood pressure was also taken, by the method recommended by the committee of the British Cardiac Society and the American Heart Association.

The patient was first graded according to his casual diastolic pressure as follows: Grade I, 96-105; Grade II, 106-115; Grade III, 116-125; Grade IV, more than 125. If the basal 
Fig. 1.-Three specimen phonocardiograms. $\quad$ St $=$ stethoscopic trace. Log. = logarithmic trace. $1=1$ st sound. $2=2$ nd sound. $11^{\prime}=$ split 1st sound. $\quad \mathrm{a}=$ auricular vibrations. $\mathbf{S}=$ indeterminate gallop. Scale: $1 \mathrm{~cm} .=0.2 \mathrm{sec}$.

(A) Split 1st sound. Auricular vibrations (preceding the apex of the electrocardiogram $R$ wave) are present in the stethoscopic but not in the logarithmic trace.

(B) Auricular gallop. Auricular vibrations are present in both stethoscopic and logarithmic traces.

(C) Indeterminate gallop. Owing to tachycardia (rate 130) the gallop sound (S) satisfies the criteria for both rapid filling gallop $(<0.2$ sec. after onset, 2 nd sound) and auricular gallop (between apex of $P$ wave and apex of $R$ wave in electrocardiogram $r$ e f e r e n c e trace).
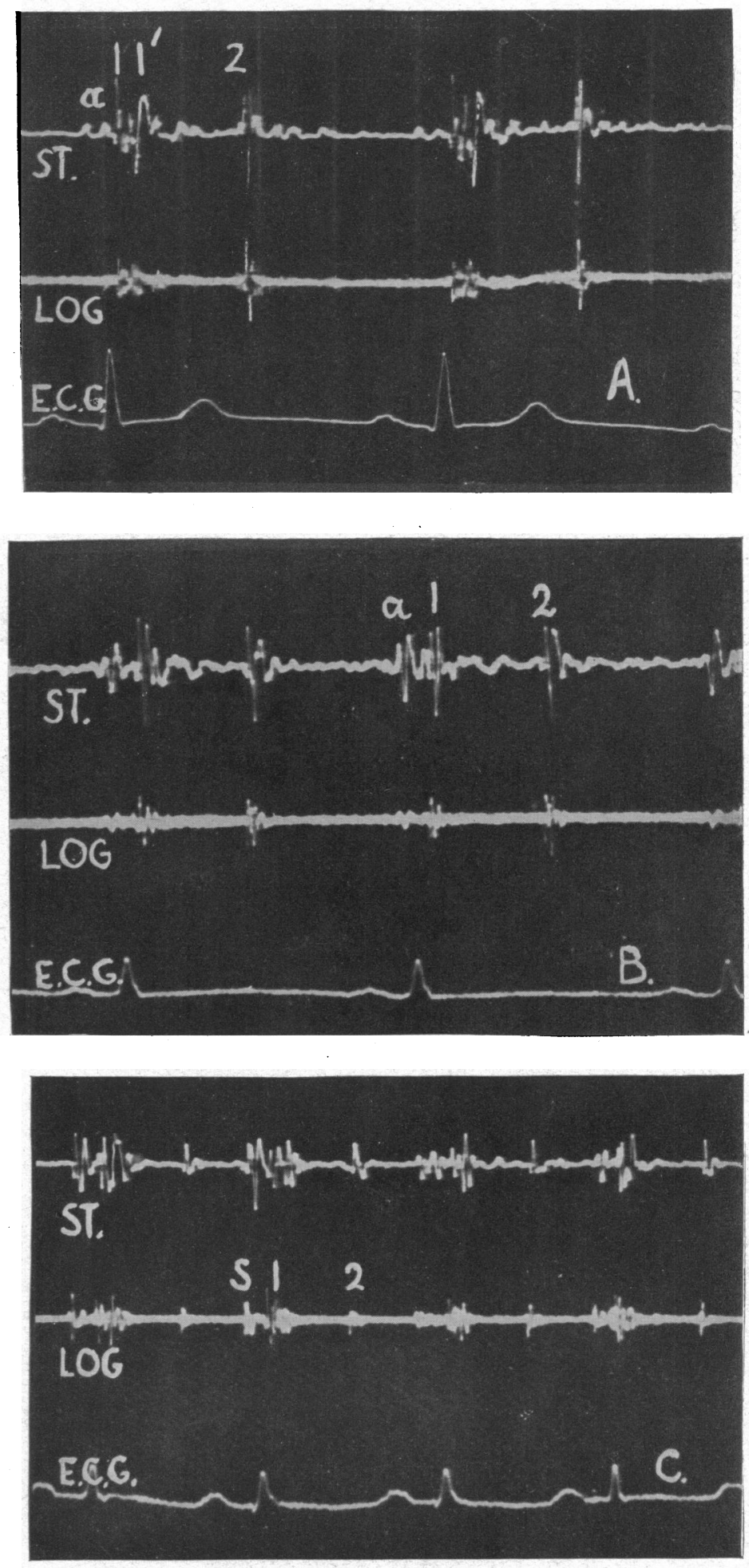
diastolic pressure was more than $20 \mathrm{~mm}$. below the lowest figure of the previously assigned casual diastolic pressure grade, this grade was lowered by 1, provided that the casual pressure was not above $135 \mathrm{~mm}$. Hg. Nine were lowered in this way. One patient, with a casual pressure of 210/128 and a basal pressure of 128/80 was lowered from Grade IV to Grade II.

Heart size. The size of the heart was judged by eye from a postero-anterior teleradiogram. Thirteen cases were screened as well. The grades (I-IV) were normal limits, slight enlargement, moderate enlargement, and gross enlargement.

Degree of cardiac failure. The following four grades were recognized: no dyspnœa on level walking; dyspnœa on level walking; dyspnœa at rest (orthopnœa and paroxysmal dyspnœa) and right-sided cardiac failure (with raised venous pressure). Breathlessness on hills only, may often have been due to early left ventricular failure, but the significance of minor degrees of this symptom is difficult to assess.

Electrocardiographic changes. An abnormal group was recognized, comprising cases with left ventricular strain, old myocardial infarction, bundle branch block, and atypical tracings, and a normal which included simple left axis deviation.

\section{RESULTS}

The final clinical and phonocardiographic diagnoses of the heart sounds are shown below.

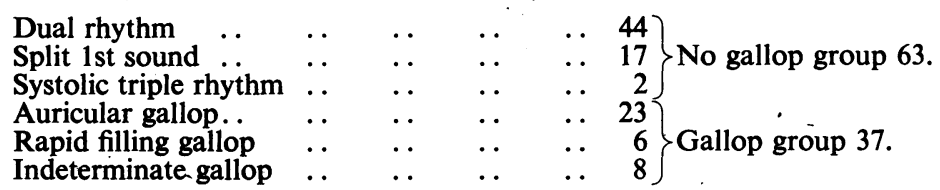

Of 41 cases believed on clinical grounds to have gallop rhythm 8 had no good phonocardiographic evidence of it; most of them having split first sounds. Of 23 cases judged clinically to have splitting of the first sound 4 were shown to have auricular gallop. The clinical findings are shown below.

$\begin{array}{llccc} & & \text { Blood pressure } & \text { Heart size } & \text { Degree of failure } \\ \text { Grade I } & \ldots & 16 & 28 & 46 \\ \text { Grade II } & \ldots & 25 & 25 & 35 \\ \text { Grade III } & \ldots & 26 & 22 & 11 \\ \text { Grade IV } & \ldots & 33 & 25 & 8\end{array}$

The electrocardiographic findings were abnormal in 52 cases: left ventricular strain in 34 , old myocardial infarct in 3 , atypical in 8 , and bundle branch block in 7 cases. They were normal in the remaining 48 , though 30 showed some left axis deviation. The $\mathrm{P}-\mathrm{R}$ interval was less than $0.16 \mathrm{sec}$. in 23; between 0.16 and 0.20 in 63 ; and greater than $0.20 \mathrm{sec}$. in 7 : the remaining 7 had auricular fibrillation.

Fig. 2 shows the number of cases with and without gallop rhythm in each grade of blood pressure, heart size, and degree of cardiac failure; and in those with normal and abnormal electrocardiograms. A distinct tendency is shown for the more advanced cases to be associated with gallop rhythm, which was present in more than half the patients in the fourth grades. The three different gallop groups are analysed below.

Auricular gallop group. This comprised 23 cases, 10 men and 13 women of average age 51 years (range 23-71). At the time of recording, the average pulse rate was 90 (range 60-110).

Fig. 2 reveals a statistically significant correlation between auricular gallop and Grade IV hypertension and also between auricular gallop and an abnormal electrocardiogram. There is no such striking correlation with Grade IV heart size or Grade IV cardiac failure. None of the cases with the lowest grade of hypertension had auricular gallop. It is of interest that $6(26 \%)$ of the auricular 


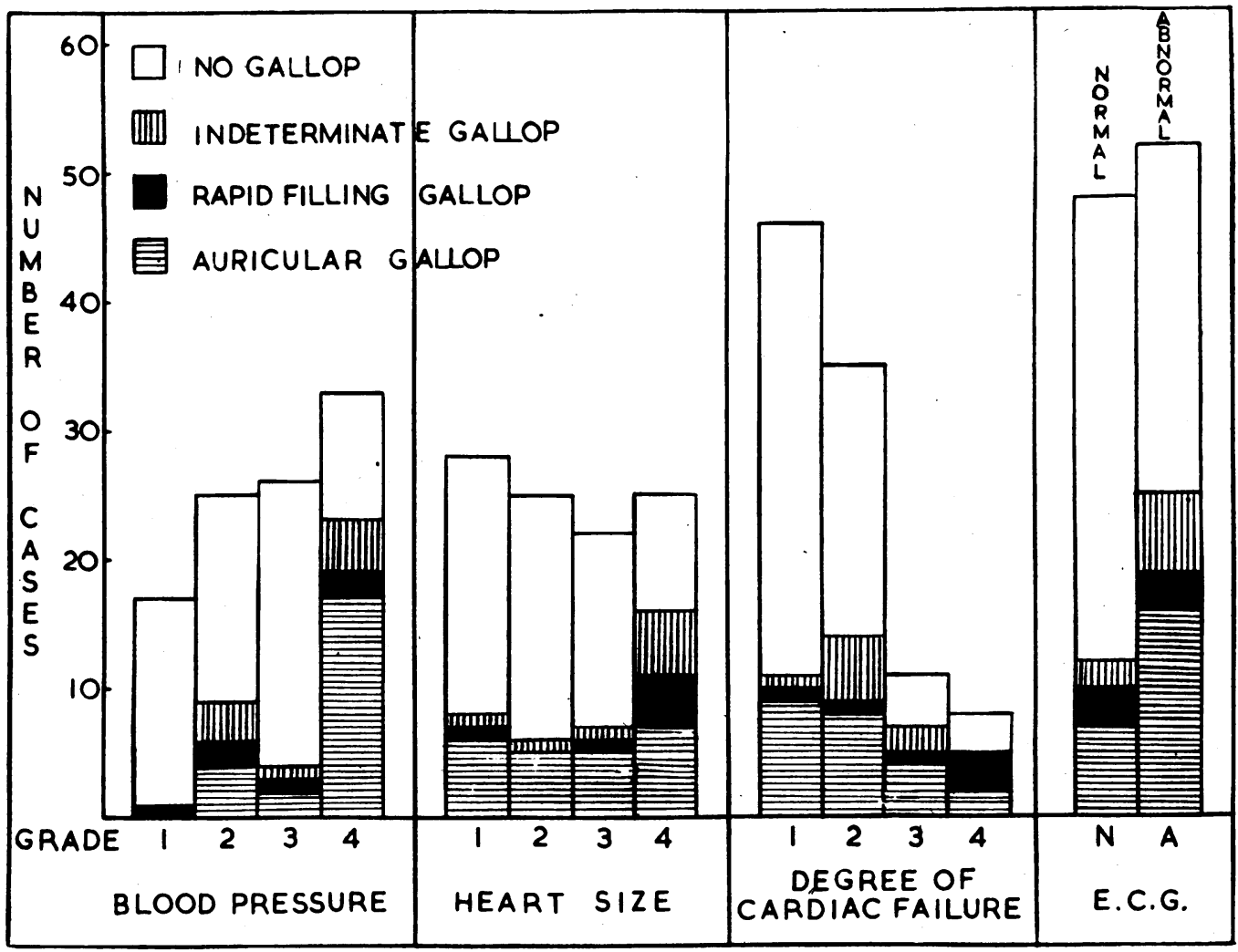

FIG. 2.-Number of cases with and without gallop rhythm in each grade (see text).

gallop cases had apparently normal sized hearts, $9(39 \%)$ had no breathlessness on walking on the flat, and $7(30 \%)$ had electrocardiograms within normal limits. Three of the cases had neither enlargement of the heart nor. shortness of breath on the flat. One patient, aged 23, with Grade IV hypertension and a loud auricular gallop, was able to enjoy a full day's shooting expedition.

No correlation was observed between the loudness of the auricular gallop and the severity of the case. Nor was any relation noticed between the severity of the case and the interval between the gallop and first sound. Five of the auricular gallop cases had P-R intervals exceeding $0.2 \mathrm{sec}$.; they were in other respects typical of the group.

Rapid filling gallop group. This comprised 6 cases; 2 men and 4 women of average age 63 years (range 52-71). Their average pulse rate at the time of recording was 93 (range 75-106). This group was unfortunately too small to allow firm conclusions to be drawn from it, but 4 of the 6 cases had gross enlargement of the heart, and 3 of them had right-sided cardiac failure, which is a statistically significant correlation, as there were only 8 cases of right-sided failure in the whole series $\left(\chi^{2}=15 \cdot 3\right)$. One case, on the other hand, had neither cardiac enlargement, breathlessness when walking on the level, nor electrocardiographic change.

Two of the three gallops heard best in the xiphisternal region were rapid filling gallops. Both were associated with right-sided cardiac failure.

Indeterminate gallop group. This comprised 8 cases; 5 men and 3 women, of average age 51 years (range 31-60). At the time of recording the average pulse rate was 113 (range 100-125). Reference to Fig. 2 shows that 5 of the 8 cases had gross enlargement of the heart; 1, however, had a normal sized heart on screening and was not breathless on the flat. Six of the 8 cases had loud gallops; the gallop sometimes being the loudest of the three sounds. 
The site of maximum audibility of the gallop sound is shown below.

\begin{tabular}{lcccccc}
\multicolumn{2}{r}{ Site best heard } & & $\begin{array}{c}\text { Auricular gallop } \\
\text { cases }\end{array}$ & $\begin{array}{c}\text { Rapid filling } \\
\text { gallop cases }\end{array}$ & $\begin{array}{c}\text { Indeterminate } \\
\text { gallop cases }\end{array}$ \\
Apex &. & $\ldots$ & $\ldots$ & 17 & 2 & 3 \\
Xiphisternum & $\ldots$ & $\ldots$ & 0 & 2 & 1 \\
Both equally & $\ldots$ & $\ldots$ &. & 6 & 2 & 4
\end{tabular}

\section{Discussion}

An interesting finding was the commonness of gallop rhythm in hypertension when specially sought. The best available evidence of its absolute incidence is Garvin's (1943) finding, that 47 per cent of hypertensive patients who died a cardiac death had previously had gallop rhythm. That 37 per cent. of the present series of unselected hospital patients with hypertension, and as many as 63 per cent of those with Grade III and IV cardiac failure, had gallop rhythm when examined on a single occasion, suggests that more than 50 per cent of hypertensive subjects are likely to develop gallop rhythm sooner or later, even when taking into account that some, through obesity or emphysema, will have sounds of low intensity.

If gallop rhythm is to have prognostic value, it must either be a reliable indication that a certain stage of cardiac involvement has been reached, or a sign of a rapidly advancing disease process. The present investigation, while showing a tendency for the severer cases to be associated more often with gallop rhythm, demonstrated that in hypertension it occurs over a wide clinical range. If, then, we ignore the remote possibility that gallop rhythm is in some way correlated with the rate of progress of the hypertension, it follows that gallop rhythm is not a reliable prognostic sign.

There is surprisingly little written reference to the examples, familiar to all clinicians, of gallop rhythm occurring in patients with comparatively good cardiac function, though Duchosal (1932) does say that a certain proportion of hypertensive subjects may possess well-defined gallop rhythm for years.

This finding, that gallop rhythm may be audible under widely differing conditions, is not in the least unexpected when it is appreciated that the corresponding vibrations in the normal hearts of young people vary enormously in intensity; and, moreover, that in adults great differences occur in the transmitting properties of the lungs from emphysema and of the chest wall as a result of rigidity or obesity. It is of some interest that 43 per cent of the non-gallop cases were obese, as compared with only 22 per cent of the gallop cases, though it is true that the obese and non-obese groups were not strictly homogeneous.

Fig. 3, which compares the clinical findings in the 37 gallop cases and in the 52 with abnormal electrocardiograms, suggests that gallop rhythm has about the same overall significance as has any abnormality in the electrocardiogram. It is not doubted that gallop rhythm is a valuable clinical sign in the detection of heart disease, but it is probably a poor guide to prognosis. There are better methods for assessing the cardiac status. If two patients had the same history, blood pressure, heart size, degree of cardiac failure, and pulse rate, and one of them had gallop rhythm, there is no evidence to show that the latter would have the worse prognosis.

In addition to the claim that gallop rhythm is useful prognostically, Evans (1943), has asserted that rapid filling gallop is a sign of right- and auricular gallop of left-sided cardiac failure. In the present series, only 2 out of 23 with auricular gallop, and as many as 3 out of 6 with rapid filling gallop, had right-sided cardiac failure, thus giving some support to Evans' contention. There is also some corroboration for the view originally propounded by Potain (cited by Holt, 1927), that the gallop may be right-sided (i.e. heard best towards the xiphisternum) in cases of right-sided cardiac failure. Of the 5 cases with right-sided cardiac failure, 2 were heard best in the xiphisternum region, 1 in the apical region, and 2 equally well at both. The only other right-sided gallop was an indeter- 


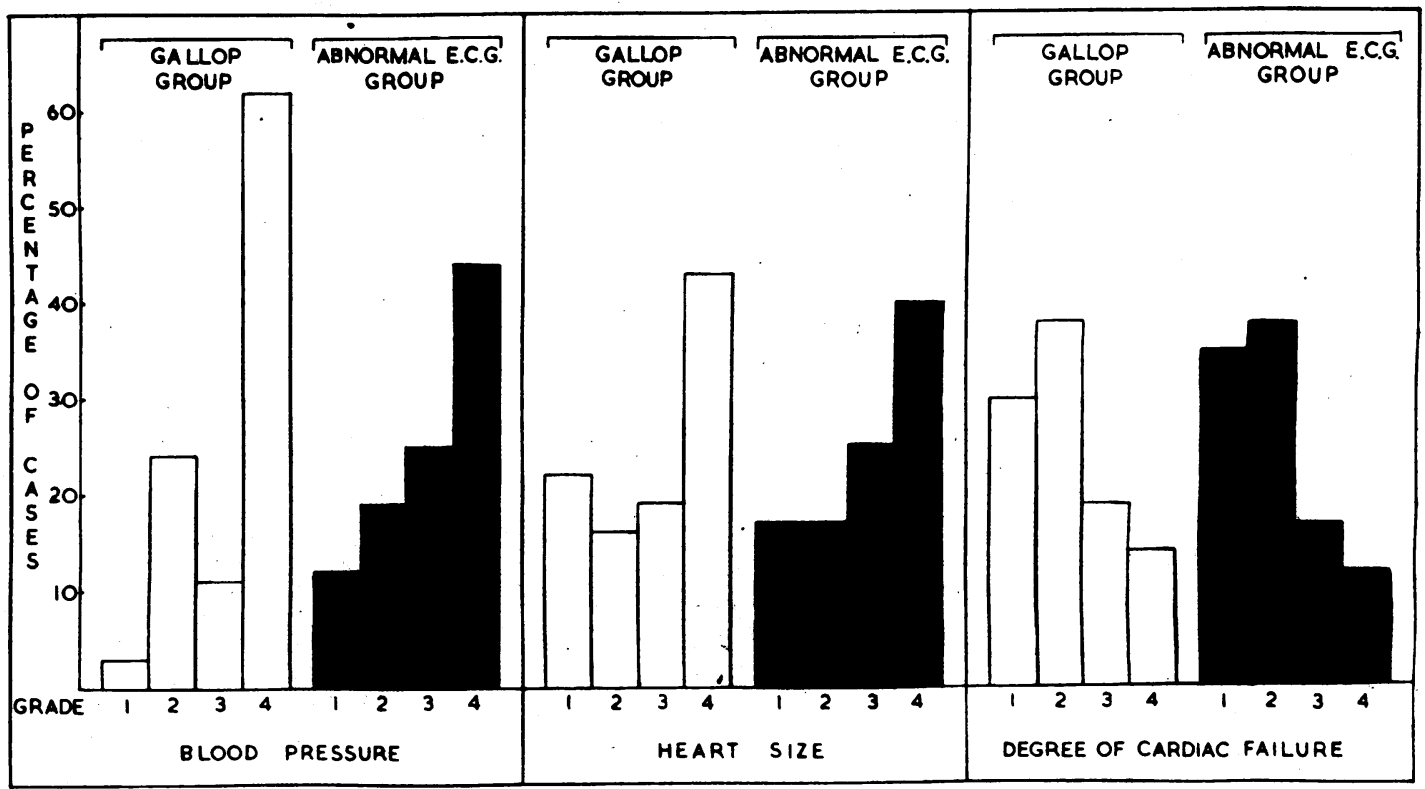

FIG. 3.-The clinical findings as regards blood pressure, heart size, and degree of cardiac failure are shown to be similar in the gallop rhythm group ( 37 cases) and the abnormal electrocardiogram group (52 cases).

minate gallop. It would, however, be rash to assert that right-sided gallop always arose in the right ventricle. Contrary to the findings of Evans (1943), none of the auricular gallop sounds was most audible near the xiphisternum.

\section{SUMMARY}

Gallop rhythm as defined was heard and recorded phonocardiographically in 37 of 100 patients with hypertension.

Poor correlation was shown between gallop rhythm and the degree of heart disease as judged by blood pressure, heart size, degree of cardiac failure and electrocardiographic abnormality.

It is suggested that gallop rhythm has little value in prognosis, as it occurs in a wide range of clinical circumstances.

A tendency was shown for " rapid filling" gallop to be associated with right-sided cardiac failure.

This paper is taken from a Cambridge M.D. thesis. I wish to thank Professor F. H. Smirk for the generous provision of facilities in his Department at Otago University, and to Professor E. P. Sharpey-Schafer and A. C. Dornhorst for helpful criticism.

\section{REFERENCES}

Duchosal, P. (1932). Amer. Heart J., 7, 613.

Evans, W. (1943). Brit. Heart J., 5, 205.

Frost, J. (1949). Acta. med. Scand., 133, 268.

Garvin, C. F. (1943). Amer. J. med. Sci., 205, 814.

Holt, E. (1927). Amer. Heart J., $2,453$.

Lian, C., Minot, G., and Welti, J. J. (1941). Phonocardiographie Auscultation Collective, Paris.

Miles, B. E. (1950). M.D. Thesis, Cambridge.

Orías, O., and Braun-Menéndez, E.(1939). The Heart Sounds in Normal and Pathological Conditions. 1st ed., London.

Rappaport, M. B., and Sprague, H. B. (1942). Amer. Heart J., 23, 591.

Wolferth, C. C., and Margolies, A. (1931). Med. Clin. N. Amer., $14,897$. 